\title{
Terahertz time-domain transmission and reflection spectroscopy of niobium
}

\author{
Taeyoon Hong ${ }^{a}$, Kyujin Choi ${ }^{\mathrm{a}}$, Byoung-Cheol Park ${ }^{\mathrm{a}}$, Taewoo Ha ${ }^{\mathrm{a}}$, Kyung Ik Sim ${ }^{\mathrm{a}}$, Dong-Gwang Ha ${ }^{\mathrm{b}}$, \\ Yonuk Chong ${ }^{\mathrm{b}}$, and Jae Hoon Kim ${ }^{*}$, \\ ${ }^{\mathrm{a}}$ Department of Physics, Yonsei University, Seoul 120-749 Korea \\ ${ }^{\mathrm{b}}$ Korea Research Institute of Standards and Science, Daejeon, Korea
}

(Received 28 February 2013; revised 7 March 2013; accepted 11 March 2013)

\begin{abstract}
We have developed a terahertz time-domain spectroscopy (THz-TDS) system for transmission and reflection measurements of metallic thin films. Using our THz-TDS system, we studied the conventional superconductor niobium $(\mathrm{Nb})$ in the normal state in the spectral range from 5 to $50 \mathrm{~cm}^{-1}$. Both the real and imaginary parts of the conductivity are acquired without Kramers-Kronig analysis. $\mathrm{Nb}$ exhibits a nearly frequency independent real conductivity spectrum in the terahertz range, with a very small imaginary part.
\end{abstract}

Keywords : Terahertz spectroscopy, Niobium, Superconductor

\section{INTRODUCTION}

테라헤르츠 및 원적외선 영역에서의 초전도체의 광학 측정은 역사적으로 초전도의 기원을 이해하고 Bardeen-Cooper-Schrieffer (BCS) 이론 [1]을 정립하는데 중요한 역할을 하였다. 다양한 초전도체의 에너지 갭 [2-7]이 이 영역에 존재하고 준입자 여기 흡수 및 초전도 불균일성 집단 여기 흡수 [8] 또한 이 영역에서 보고되고 있으므로 테라헤르츠는 연구 가치가 매우 높은 영역이라 할 수 있겠다.

테라헤르츠 시분해 분광법 (Terahertz Time-Domain Spectroscopy: THz-TDS) [9]은 타 측정기법에 비해 상대적으로 최근에 개발되어 활발히 응용되고 있는 측정기술로서 다양한 특장점을 가지고 있다. 첫째, 전자기파의 진폭 및 위상을 동시에 측정하므로 Kramers-Kronig 관계를 사용하지 않고도 복소 투과 및 반사 계수에서 바로 복소 광학상수 계산이 가능하다. 둘째, 기존의 열 광원과 비교하여 휘도가 매우 높고 결맞은 탐지 방식을 쓰므로 매우 훌륭한 신호 대 잡음비를 얻을 수 있다. 셋째, 수 피코초 폭의 펄스를 사용하기 때문에 기판내 반사에 의한 펄스를 시간적으로 분리하는 것이 가능하여 Fabry-Perot 간섭을 제거할 수 있다.

전술한 테라헤르츠 시분해 분광법을 사용하여 8.3 켈빈의 초전도전이온도 $\left(\mathrm{T}_{\mathrm{c}}\right)$ 와 $24 \mathrm{~cm}^{-1}$ 정도의 초전도 에너지 갭 $(2 \Delta)$ [2, 3] 을 갖는 전통적인 초전도체 나이오붐 $(\mathrm{Nb})$ 에 대한 저온 측정의 예비단계로서 상온에서의 정상상태에 대한 투과 및 반사 실험을 $5-50 \mathrm{~cm}^{-1}$ 영역의 주파수에서 수행하였다.

\section{EXPERIMENTAL}

\footnotetext{
* Corresponding aurhor: super@yonsei.ac.kr
}

Fig. 1은 본 연구실의 $\mathrm{THz}-\mathrm{TDS}$ 투과/반사 시스템의 개략도이다. Ti:Sapphire 펄스 레이저 (파장 $800 \mathrm{~nm}$, 폭 $\sim 70 \mathrm{fs}$, 펄스 반복률 $\sim 80 \mathrm{MHz}$ ) 와 광전도(photoconductive) 안테나를 사용하여 테라헤르츠 펄스를 발진시키고 탐지한다. 발진기와 탐지기로 사용되는 광전도 안테나는 저온에서 성장된 $\mathrm{GaAs}$ 기판 위에 금 전극을 전기쌍극자 패턴으로 증착한 것으로 테라헤르츠 펄스 발진과 탐지를 위해 광범위하게 사용되는 것이다.

투과 실험을 위하여 테라헤르츠 펄스를 포집하고 시료에 초점을 맞추기 위하여 off-axis paraboloidal 거울을 사용하였다. 반사 실험의 경우 광섬유를 이용하여 펨토초 레이저 펄스와 발진기 및 탐지기를 시료에 접근시킨 후 발생된 테라헤르츠 펄스를 시료에 $15^{\circ}$ 정도 각으로 입사/반사시켜 실험을 수행하였다.

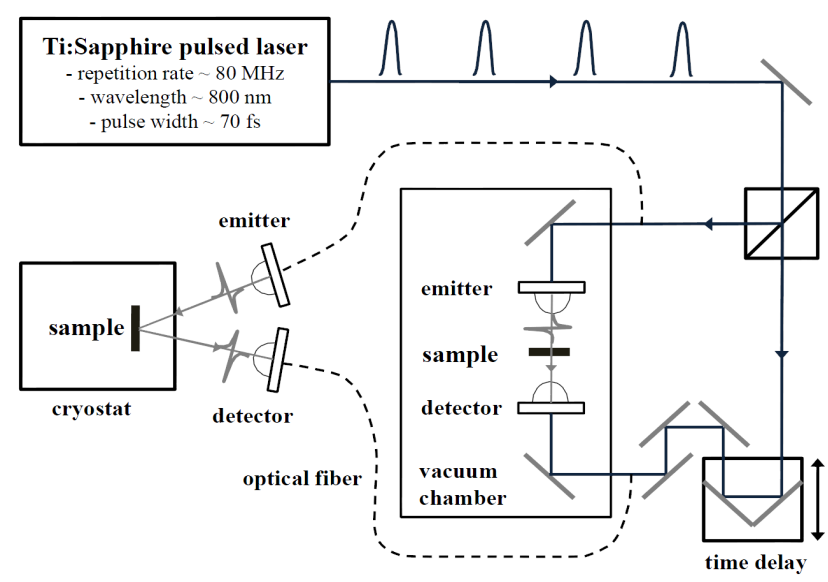

Fig. 1. A schematic diagram of our THz-TDS transmission and reflection system. 

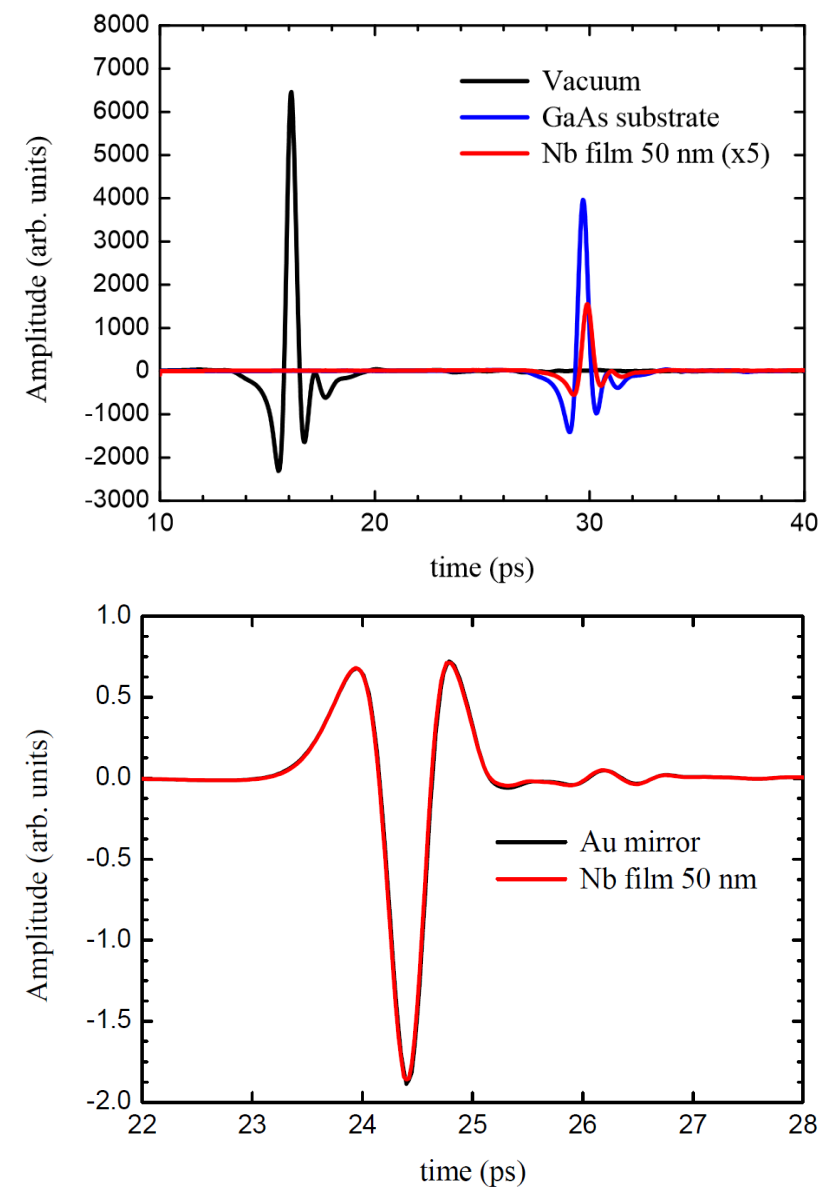

Fig. 2. Time-domain waveforms transmitted through vacuum (black line), a GaAs substrate (blue line), and our $\mathrm{Nb}$ film (red line) evaporated on the GaAs substrate (scaled by a factor of 5) (top). Time-domain waveform reflected from a gold mirror and our $\mathrm{Nb}$ film (bottom).

반사 실험 수행 시 시료와 반사표준용 금 거울간의 위치 차이가 상당한 오차를 가져오기 때문에 이를 방지하기 위하여 특별히 고안한 시료 홀더를 사용하여 오차를 줄였다.

$\mathrm{Nb}$ 박막 시료는 한국표준과학연구원에서 두께 1.5 $\mathrm{mm}$ 의 부도체 GaAs 기판 위에 sputtering 기법으로 50 $\mathrm{nm}$ 의 두께로 증착되었으며 본 실험실의 $\mathrm{THz}-\mathrm{TDS}$ 장비를 사용하여 $\mathrm{Nb}$ 박막과 금거울의 투과 및 반사 테라헤르츠 펄스의 세기를 시간에 대한 함수로 획득한 후 푸리에 변환하여 복소 스펙트럼을 추출한 후에 투과도와 반사도를 계산하였다.

Fig. 2 은 진공, GaAs 기판, $\mathrm{Nb}$ 박막의 투과 테라헤르츠 펄스 세기를 시간의 함수로 획득한 것이다. 진공을 투과한 펄스의 피크와 $\mathrm{GaAs}$ 기판을 투과한 펄스의 피크의 시간 차이가 13.5 피코초 정도인 것을 확인할 수 있는데 이것은 테라헤르츠 영역에서 굴절률이 3.7 인 $1.5 \mathrm{~mm}$ 두께의 $\mathrm{GaAs}$ 기판을 빛이 투과하는데 걸리는 시간으로 계산이 가능하다. GaAs 기판 위에 증착된 $\mathrm{Nb}$ 박막의 두께가 50 $\mathrm{nm}$ 로 매우 얇지만 금속성을 나타내기에는 충분하여 투과 펄스의 세기가 매우 작아 자세히 보기 위하여 5 배 확대하여 표시하였다. Fig. 2(bottom)은 반사표준용 금 거울과 $\mathrm{Nb}$ 박막에서 반사된 테라헤르츠 펼스를 시간에 대한 함수로 획득한 것이다. $\mathrm{Nb}$ 시료의 금속성이 좋아 반사율이 표준용 금 거울 결과와 거의 같게 나온 것을 확인할 수 있다.

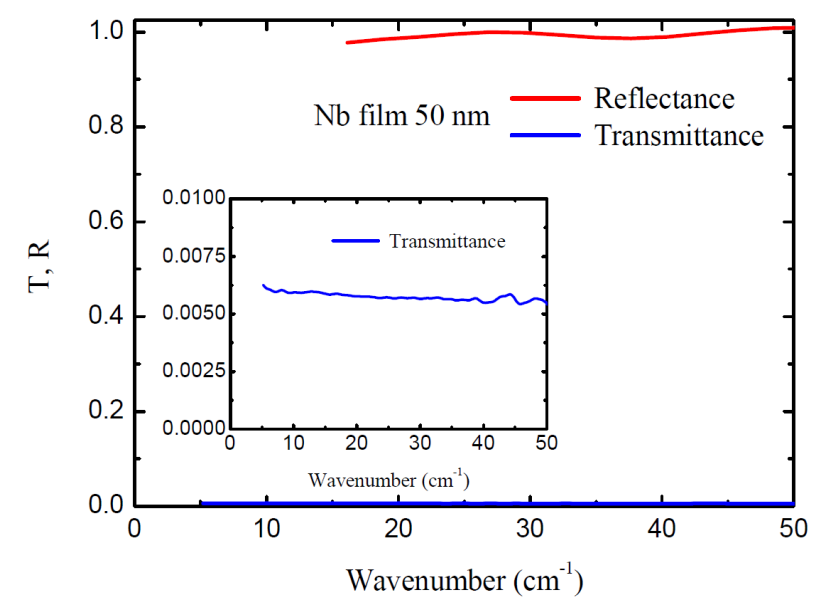

Fig. 3. The reflectance and transmittance spectra of our $\mathrm{Nb}$ film.

\section{RESULTS AND DISCUSSION}

Fig. 3에서도 역시 $\mathrm{Nb}$ 박막의 반사율과 투과율로부터 $\mathrm{Nb}$ 이 매우 좋은 전도체임을 확인할 수 있다. 반사율의 경우 15 에서 $50 \mathrm{~cm}^{-1}$ 까지의 영역에서 오차범위 이내로 1 에 가까운 결과를 보이고 투과율의 경우 5 에서 $50 \mathrm{~cm}^{-1}$ 까지의 전 측정영역에서 $0.6 \%$ 의 거의 일정한 값을 갖는 것을 확인할 수 있었다.

앞서 계산된 $\mathrm{Nb}$ 박막의 복소 투과계수와 미리 측정된 $\mathrm{GaAs}$ 기판의 복소 굴절률을 가지고 아래의 공식 [5]을 사용하여 $\mathrm{Nb}$ 박막의 복소 동전도도 $\sigma(\omega)=\sigma_{1}(\omega)+i \sigma_{2}(\omega)$ 를 각주파수 $\omega$ 의 함수로서 계산하였다.

$$
\sigma(\omega)=\frac{\left(n_{s}+1\right)\left(t_{s} / t_{f}-1\right)}{Z_{0} d} .
$$

여기서 $Z_{0}$ 는 자유 공간의 임피던스, $d$ 는 박막의 두께, $n_{s}$ 는 기판의 복소 굴절률, $t_{f}$ 와 $t_{s}$ 는 각각 박막과 기판을 모두 투과한 복소 투과계수와 기판만을 투과한 복소 투과계수를 말한다. $\mathrm{Nb}$ 박막의 두께가 $50 \mathrm{~nm}$ 로 $n_{f} \omega d / c<<1$ ( $n_{f}$ 는 박막 복소 굴절률, $c$ 는 진공중 광속) 가정이 잘 맞기 때문에 위의 공식을 사용하여 복소 동전도도를 성공적으로 계산할 수 있었다.

Fig. 4는 계산된 복소 동전도도와 Drude model fitting [10] 결과로서 Drude Model Fitting 파라미터로는 $\sigma_{D C}=30,545 \Omega^{-1} \mathrm{~cm}^{-1}, \gamma=5,500 \mathrm{~cm}^{-1}$ 을 사용 하였다. 복소 동전도도의 실수부와 허수부를 보면 측정된 전 영역에서 거의 일정한 값을 갖는 것을 확인할 수 있는데 이것은 금속의 복소 동전도도를 기술하는 Drude model 에서 충돌률 $\gamma$ 보다 매우 낮은 주파수 영역에서의 전도도 예상치와 일치하는 결과이다. 전도도 실수부의 크기를 보면 $3 \times 10^{4}$ 정도로 backward wave oscillator를 사용한 기존 문헌값 $(\mathrm{Nb}$ 박막 두께 $15 \mathrm{~nm}$ ) [3] 과 비교하면 $70 \%$ 정도의 값을 보이는 것을 확인하였다. 


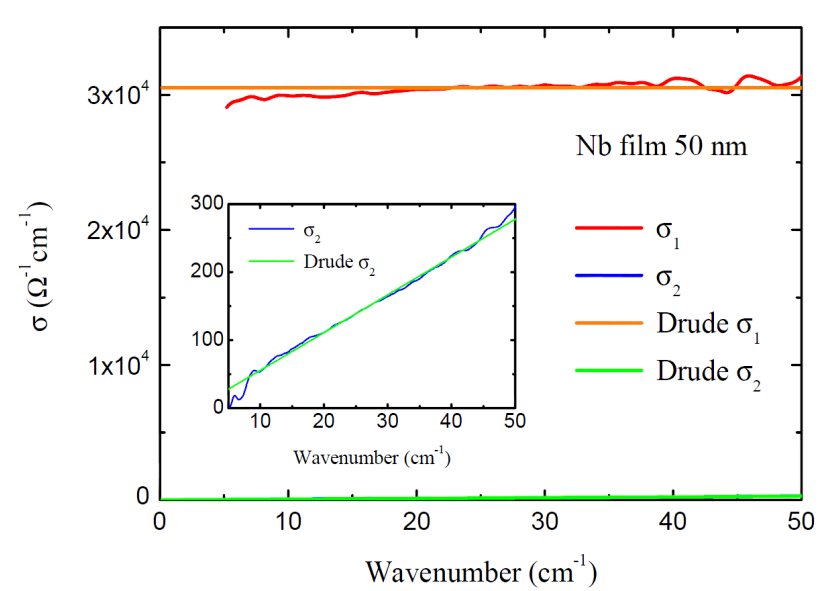

Fig. 4. The real and imaginary parts of the conductivity of our $\mathrm{Nb}$ film as a function of frequency. The predictions of the Drude model are also shown.

\section{CONCULSION}

우리는 테라헤르츠 시분해 투과 및 반사 분광법을 사용하여 $50 \mathrm{~nm}$ 두께 단일원소 금속 초전도체 $\mathrm{Nb}$ 박막의 투과, 반사율 및 복소 동전도도를 결정하였다. $\mathrm{Nb}$ 의 상온 정상상태 동전도도 결과는 Drude model의 예측과 매우 잘 일치한다는 것을 확인하였다. 본 연구는 향후 저온실험에서 의 측정결과와 비교하여 초전도 gap을 결정하는 자료로 이용될 것이다.

\section{ACKNOWLEDGMENT}

This work was financially supported by Basic Science Research Program through the National Research Foundation of Korea (NRF) by Ministry of Science and Technology (2010-0012991).

\section{REFERENCES}

[1] J. Bardeen, L. N. Cooper, and J. R. Schrieffer, Phys. Rev. 108, 1175 (1957).

[2] Martin C. Nuss, K. W. Goossen, J. P. Gordon, P. M. Mankiewich, and M. Bhushan, J. Appl. Phys. 70, 2238 (1991).

[3] A. V. Pronin et al., Phys. Rev. B 57, 14416 (1998).

[4] N. Drichko, P. Haas, B. Gorshunov, D. Schweitzer, and M. Dressel, Europhys. Lett. 59, 774-778 (2002).

[5] Robert A. Kaindl et al., Phys. Rev. Lett. 88, 027003 (2002).

[6] M. Ortolani et al., Phys. Rev. Lett. 97, 097002 (2006).

[7] A. Perucchi et al., Eur. Phys. J. B 77, 25-30 (2010).

[8] J. Corson, J. Orenstein, Seonshik Oh, J. O’Donnell, and J. N. Eckstein, Phys. Rev. Lett. 85, 2569 (2000)

[9] M. C. Nuss and J. Orenstein, "Millimeter and Submillimeter Wave Spectroscopy of Solids", edited by G. Grüner, Springer-Verlag, Berlin, 7-50 (1998).

[10] Dressel, M.; Gruner; G. Electrodynamics of Solids: Optical Properties of Electrons in Matter; Cambridge University Press: Cambridge, 2002. 